\title{
Return to Society: A Case Study of the Psychology Impact of Taekwondo Training on the Handicapped Athlete
}

\author{
Ziyi Xia1, HongJian $\mathrm{He}^{2}$, Jianzhong $\mathrm{Wu}^{\mathbf{1}^{*}}$ \\ ${ }^{1}$ Sport Coaching College, Beijing Sports University, Beijing, China \\ ${ }^{2}$ Faculty of Physical Education and Sport, Charles University, Beijing, China \\ Email: ^13522175894@163.com
}

How to cite this paper: Xia, Z. Y., He, H. J., \& Wu, J. Z. (2020). Return to Society: A Case Study of the Psychology Impact of Taekwondo Training on the Handicapped Athlete. Open Journal of Social Sciences, 8, 228-238.

https://doi.org/10.4236/jss.2020.83021

Received: December 27, 2019

Accepted: March 17, 2020

Published: March 20, 2020

\begin{abstract}
This article takes advantage of the author's taekwondo teaching opportunities for handicapped athlete in Beijing para taekwondo team. Using literature, interview and qualitative research methods to analyze the psychology impact of handicapped athletes' participate in taekwondo on their return to society. The main contributors to improve their mental health are increased about Anti-frustration ability increased (12/12), respect for others (7/7), reduced inferiority and loneliness (5/5). Participating in Taekwondo training improved mental health of handicapped people, especially their sense of identity. The results also showed the positive influence not only in evaluation by others but also their future career developments, ultimately lead them better integrate into society.
\end{abstract}

\section{Keywords}

Taekwondo, Psychology Impact, Handicapped Athlete

\section{Introduction}

In 2015, the international paralympic committee (IPC) held in the united Arab emirates confirmed taekwondo as the official event of the 2020 paralympics in Tokyo Japan (Lin et al., 2011), and was successively selected as the official event of the 2024 paralympics in Paris. At the end of 2019, disabled taekwondo was confirmed as the official event of the 2022 Asian paralympic games (Tang, 2005).

Studies have shown that there is a serious lack of psychological intervention after disabled people are disabled, which leads to a series of psychological prob- 
lems such as low self-esteem and sense-loss (Lin, 2011). Studies show that participation in sports has a positive effect on the mental state of the disabled (Tang, 2005). Participating in sports can meet the growing spiritual and cultural needs of the disabled, improve their physical and mental health level and other aspects of quality, is an effective way for them to learn self-reliance, self-reliance, self-expression, self-transcendence, and equal participation in social life (Valliant, Bezzubyk, \& Daley, 1985).

\section{Research Method}

\subsection{Objective of Study}

Psychology Impact of Taekwondo Training on the Handicapped Athlete.

\subsection{Method}

A total sample of 18 handicapped athletes (age range from 17 to $29 ; 11$ male, 7 female; 3 physical handicapped K42-K44 athletes, 15 hearing handicapped KP60 athletes) were recruited from Beijing Handicapped Taekwondo Team. All subjects participated in one-on-one interviews focused on their changes in mental health. The semi-structured outline was applied by the interview and included 7 questions. During the period of interview, the recording pen was used to record the entire interview text. With the standard procedure of the grounded theory, interview data will be tabulated based on the number of mentions. In the present study, the appropriate IRB approval has been obtained from Beijing Sport University.

\section{Results and Analysis}

\subsection{Results of Preliminary Analysis of Original Materials}

1) read the original materials repeatedly to find out 16 units of thinking.

2) login the thinking unit to form a first-level code.

3) the person-time frequency statistics of thinking units are conducted, and the following level of coding information is finally obtained, as shown in Table 1.

\subsection{Results of In-Depth Analysis of First-Level Coding}

\subsubsection{Generic Analysis of First-Level Codes}

The first generic analysis of 16 first-order codes in Table 3 classifies the thinking units with the same attributes into the same category.

Finally, six types of secondary codes are formed: 1) psychological changes 2) physical changes 3) evaluation of changes 4) communication changes 5) future financial security 6) future career basis, as shown in Table 2.

\subsubsection{Secondary Codes are Analyzed One by One as Follows}

1) psychological changes

Disabled people are a special group. In addition to the great inconvenience 
Table 1. One level coded login status.

\begin{tabular}{|c|c|c|}
\hline serial number & Content & Number/times of mention \\
\hline 1 & Respect for others & $7 / 7$ \\
\hline 2 & Understand the etiquette & $6 / 7$ \\
\hline 3 & Reduced loneliness & $5 / 5$ \\
\hline 4 & Anti-frustration ability increased & $12 / 12$ \\
\hline 5 & Body Shape change & $4 / 5$ \\
\hline 6 & Smile increases & $8 / 9$ \\
\hline 7 & Physical fitness enhancement & $13 / 14$ \\
\hline 8 & Lovers feel more secure & $1 / 3$ \\
\hline 9 & Positive social evaluation & $4 / 4$ \\
\hline 10 & Equal social status & $5 / 6$ \\
\hline 11 & Increased social trust & $3 / 5$ \\
\hline 12 & Feelings of inferiority decrease & $4 / 7$ \\
\hline 13 & Bonus reward & $11 / 15$ \\
\hline 14 & Fixed wage protection & $9 / 13$ \\
\hline 15 & Expand employment channels & $5 / 7$ \\
\hline 16 & Improved self-care ability & $8 / 10$ \\
\hline
\end{tabular}

Table 2. Level 2 coding.

\begin{tabular}{|c|c|c|}
\hline Level 1 coding/content & Number/times of mention & Level 2 coding/content \\
\hline Respect for others & $7 / 7$ & \multirow{4}{*}{ psychological changes } \\
\hline Understand the etiquette & $6 / 7$ & \\
\hline Reduced loneliness & $5 / 5$ & \\
\hline Anti-frustration ability increased & $12 / 12$ & \\
\hline Body Shape change & $4 / 5$ & \multirow{3}{*}{ physical changes } \\
\hline Smile increases & $8 / 9$ & \\
\hline Physical fitness enhancement & $13 / 14$ & \\
\hline Lovers feel more secure & $1 / 3$ & \multirow[b]{2}{*}{ evaluation of changes, } \\
\hline Positive social evaluation & $4 / 4$ & \\
\hline Equal social status & $5 / 6$ & \multirow{3}{*}{ communication changes } \\
\hline Increased social trust & $3 / 5$ & \\
\hline Feelings of inferiority decrease & $4 / 7$ & \\
\hline Bonus reward & $11 / 15$ & \multirow{2}{*}{ future financial security } \\
\hline Fixed wage protection & $9 / 13$ & \\
\hline Expand employment channels & $5 / 7$ & \multirow[t]{2}{*}{ future career basis } \\
\hline Improved self-care ability & $8 / 10$ & \\
\hline
\end{tabular}


in life, their disability seriously hurts their confidence in life (Li, 2010). Not only physically, but also in terms of mental health, disabled people are more likely to have serious negative effects. However, research shows that participating in sports can help disabled people to form a positive state of mind and reduce the negative state of mind. Becoming a disabled athlete has a positive effect on the psychological changes of disabled people (Tang, 2005). According to the category analysis, it is concluded that the psychological changes of the disabled people include respecting others, knowing etiquette, decreasing loneliness and strengthening anti-frustration ability.

a) respect for others $(7 / 7)$

The basic principle of respect for others has an important impact on the return of disabled people to society and is also a psychological mechanism for the formation of good emotions. The basic meaning of respect is respect, attention, the old saying refers to the other side as higher than their own status and must pay attention to the state of mind and words and deeds, has been gradually extended to the equal state of mind and words and deeds.

Wang Feng $X$ in the respondents mentioned "in the process of training I actually think I know more respect yourself, respect others, respect for opponents for coach for his teammates, because everyone else is discriminating against us, we also don't know how to respect others, form a vicious circle, easily for this fight, now because learning taekwondo and spirit, let me learn how to respect yourself, respect others, respect other people they will like to come with me".

b) know the etiquette (6/7)

The level of etiquette quality directly affects the establishment of personal behavior and moral system and plays an important role in the cultivation and promotion of comprehensive quality. Etiquette is also the external expression of personal inner cultivation. After practicing taekwondo, disabled practitioners learn more about etiquette, such as bowing to the gym when they enter the gym, bowing to the coach when they see the coach, and bowing to each other before matching training.

Know the etiquette a total of six people mention 7 times, Wu Q. said "taekwondo practice after I know the etiquette, meet the coach to bow to bow, see the teacher, too, once I back to school to see the teacher very natural bow, stunned, the teacher said to practice tae kwon do really different, I didn't realize that later think about it, I remember it very deep".

Chen also said, "I understand the etiquette now, now I know that the bow in taekwondo also means to thank the opponent, that is, we would help our teammates tie up the protective gear and then bow, I think it is to show my gratitude, and the other side will also bow back."

The improvement of etiquette quality also plays an important role in better communication with others in the future.

c) less loneliness (5/5)

Loneliness is a reflection of a closed mind, a feeling of isolation or exclusion 
from the outside world (Tang, 2004) (http://www.worldtaekwondo.org). Generally speaking, temporary or occasional loneliness will not cause psychological behavior disorder, but long-term or severe loneliness can cause some mood disorders and reduce people's mental health level. Disabled people often have a negative psychological impact on their personal emotions due to their individual disabilities, which cannot be eliminated for a long time since the disability. After practicing taekwondo, disabled people can effectively alleviate the loneliness and have a positive impact on the development of psychology and personal emotions.

Lai hong qing mentioned "before I was lonely, because my arm is not good, so has been someone laugh at me, no one good friend with me, I very uncomfortable, I also started to don't talk with others, after practice tae kwon do slowly I found that I actually don't lonely, so many people sweat hard together I think I am a member of the Beijing I am not alone".

d) improved ability to resist setbacks (12/12)

Frustration refers to a person in a certain motivation to promote, in the process of achieving the goal encountered unable to overcome or think that they cannot overcome the obstacles or interference, resulting in tension and negative emotional reaction. Frustration tolerance is the ability of an individual to adapt to, resist and cope with setbacks. In the sports training of taekwondo, the dominant factors of competitive ability, the characteristics of movement structure and the evaluation methods of sports performance are classified as the antagonistic events of TBT, in which physical ability, skill, tactical ability, psychological ability and knowledge ability play a decisive role (https://www.paralympic.org/news/patu-apc-sign-agreement-grow-para-taekwond o). As most of the disabled practitioners had no professional training experience before, they often encountered some obstacles in the training process, and their tolerance to setbacks also changed in the process of overcoming them one by one.

"Heel inflammation, can't walk! Do not dare to touch the ground, the coach also a strong let hard kick, life is better than death! But in the process of practice the next coach told me to insist, to have the willpower, I think people want to work hard all their lives what is greater than the national honor? You once such efforts, what difficulties in the future, what setbacks can hinder your progress? Your life is so high, what kind of harm, suffering is worth you to care about? I am now more able to understand the meaning of not giving up, and I can insist on anything in the future." Wang also mentioned, "My heart has changed a little bit. Now I often think that I have survived all this hard training. What's so scary about it?"

2) physical changes

Due to the particularity of disabled people, disabled people often hold negative emotions in self-body cognition, mainly because of their disability in different body positions, they more expect to have a strong and healthy body, and the 
strong and healthy body will to some extent make up for the physical identity attitude of disabled people.

a) body change $(4 / 5)$

Four of the interviewees mentioned five body changes, which made them change their recognition of body and increase their confidence.

"Because I am a boy, I am deaf and thin, I think I am weak, but practicing taekwondo can make me stronger, can make me more like a boy, more confident. Now I have gained a lot of weight and my legs are stronger, I think I am more like a boy. My mother also wants me to continue training to strengthen my body.

Peng J also said, "I have lost weight. I look more energetic than before! I was very fat before have 200 many catties, now I have only 140 catties still have 8 pack abdominal muscle, I didn't take a picture before but now thin take a picture hair friend circle every day, still have a lot of people thumb up support me."

b) smile increase (8/9)

In the interview, 8 interviewees mentioned that their smiles increased after participating in taekwondo (annex 2: before and after the practice). Smile refers to the expression of the face when smiling, smile is also the expression of a happy mood.

For example, Chen S mentioned, "before, I felt that life was very dark. I thought there was nothing that made me happy all year. Now, there are many things that make me happy, such as learning a movement or scoring in real combat.

Zhao X also mentioned that "I used to be quite introverted, not talkative, and very tired in designing, so I usually fell asleep when I came home. Now that I have been practicing taekwondo, I often sweat, which makes me very happy. I always smile when I come home every day.

c) physical enhancement (13/14)

During the interview, the researchers found that in this aspect, the disabled taekwondo practitioners mentioned more physical changes. High-intensity systematic training will effectively enhance the physical fitness of the disabled trainees.

"I couldn't hold on to the training in the first week, because I was so tired that I always stopped in the middle," said Zhang "after that, I could hold on and my physical strength became better."

Kong L Ming also gave a specific example to illustrate the problem. "in addition, a few days ago, our class had to go out to investigate and study the memorial hall of the May 4th movement to organize class activities. After a whole morning's shopping, they were easily so tired. And I've rarely caught a cold since I started taekwondo. Before, I was so weak that I would catch a cold once every few weeks. I've caught a cold once every year since I started taekwondo."

3) evaluation of changes

The evaluation of others is an important way to know oneself and know oneself comprehensively. Meanwhile, the evaluation of others affects the interper- 
sonal relationship in the society, which is a positive way for them to return to the society correctly.

a) increased security for lovers $(1 / 3)$

One of the interviewees mentioned that the security of lovers had been improved for three times. The lovers were important others of the disabled practitioners. The changes in the evaluation of important others made the disabled athletes more motivated and their subjective initiative increased.

"My wife says that I can protect her by practicing taekwondo," Zhang said. "every time I come home, she asks me to make two gestures. Every time I see my wife, I like to train. I think she doesn't have to be afraid outside. I can protect her.

b) increased degree of approval from others (4/4)

Disabled practitioners mentioned an increase in others' degree of affirmation after practicing taekwondo, and 4 of them mentioned an increase in others' degree of affirmation 4 times.

As liu yini said, "I forgot to mention that when I compete, my friends come to see me compete, full of praise for me, sit up and take notice."

"After many years of practicing taekwondo, my relatives came to my home and said that I practiced taekwondo and fought a lot," Chen said.

c) positive social evaluation (3/5)

Positive social evaluation is conducive to social interaction and social stability. Individuals and society are individuals who trust each other, and it requires the joint efforts of society and individuals to overcome the crisis of trust. A total of three respondents mentioned five positive social comments, as Chen said, "it was my first time to participate in such a big game, which was also an eye-opener. I don't know how much the country CARES about us, how much the society CARES about us, how much they give us clothes and shoes to play in such a big game.

"The coach told us that the country is paying attention to us now and let us work hard to enter the Olympic Games in the future. I really want to go to the Olympic Games. I have been working hard for this.

4) changes in communication

a) reduced inferiority complex (4/7)

People with a strong sense of inferiority often lack confidence in the relationship, do not have the courage, timid, go along with their own ideas, no one has a wrong thing to think is their own bad. This causes them to lose the courage and confidence to communicate. After the participants participated in taekwondo, a total of 5 disabled people mentioned 5 times that their sense of inferiority decreased in social interaction.

"I think it's opened me up since I practiced taekwondo. I used to feel inferior because I was disabled," she said.

$S$ Chen tong is a concrete example to illustrate the inferiority complex to reduce "when it comes to change before I don't speak too much in the crowd to talk is also very quiet, not like now, coach teammates have encouraged me, I can stand chest facing them, don't inferiority, tae kwon do let me and the chance of a 
tall, my special thanks to tae kwon do".

b) equal social status (5/6)

Equal social status is the basis of People's Daily social, with the daily social causes of two kinds of circumstances: discrimination and tilt to take care of, these two kinds of cases failed to help the disabled receive equal social status, have deepened its position, the vulnerable groups in society after practice tae kwon do these five people mention 6 times more equal social status.

"There used to be normal classmates who laughed at me, looked down on me and didn't play with me. Now in the taekwondo team everyone is equal and everyone treats me so well, I don't think I'm any different."

Zhang also mentioned that "after coming to the training, everyone is good. Teammates help each other and help each other equally. Before, in the society, they either ignore us or take care of us all the time.

5) future fund guarantee

Taekwondo for the handicapped athletes such as to get the result after the race will have corresponding bonus reward, it is very important for the disabled practitioners of funding, there're a total of 11 people in respondents mentioned 15 bonus reward, is referred to the greatest number, and coding of all mention of the most frequently, the visible factors has important influence on their return to society.

"I said before that if I won the competition, there would be a total bonus of $40 \mathrm{~W}$, which was unthinkable for me before. Now I have this bonus, I can start a small business or subsidize my family," said Chen. "I used to learn to design for taekwondo competitions," Chen said. "I could take the money to start my own business, and I could design for more people and taekwondo enthusiasts in the future."

b) fixed salary protection $(9 / 13)$

The fixed wage guarantee can guarantee the daily living expenses of the disabled and guarantee the basic quality of life. Among the interviewees, 9 people mentioned the fixed wage guarantee for 13 times, which is also extremely important.

$\mathrm{X}$ Feng said to the king, "I was reading in sichuan, without pay, once the Beijing to pick people told me that I can go to Beijing to practice and 3000 4000 income every month I am very happy because I was 21 years old cannot have been in deaf school, not after work, I like athletes work every month have a fixed income can also be used later, so I come to taekwondo practice and very hard."

6) future job security

a) expanding employment channels (5/7)

In today's society, the country and society actively expand employment channels for disabled people, promote employment and entrepreneurship of participants, and integrate into society. A total of five respondents mentioned that practicing taekwondo seven times can broaden their employment channels. 
"I used to play football, but now I can play taekwondo. In the future, I want to continue training and become a taekwondo coach. I want to be a coach and teach others taekwondo."

"I'm getting old now and going back to open a temple to see if I can teach kids taekwondo," peng said. "it would be nice to be a curator in the future."

"Before, I could only show others the monitoring because of my hand disability, but now I can still do something related to taekwondo when I go back," lai said.

b) improved self-care ability (8/10)

Self-care ability includes living ability, eating ability, dressing ability, communication ability, housekeeping ability, and ability to use public facilities. Self-care ability plays an important role in the social life of individuals. A total of 8 respondents mentioned that self-care ability had been enhanced after participating in taekwondo.

As Chen S mentioned, "at home before, I was not good at washing clothes and doing housework, and my mother would help me do it. Now I have come to Beijing, I have learned to tie my shoelaces with one hand, so I don't need to bother others to tie my shoelaces." "Now I have learned how to take the subway, the bus and all these things," Chen said. "I have taken them many times in Beijing, and now I can go by myself if I want to get a physical examination.”

\subsection{Results of In-Depth Analysis of Secondary Coding} Generic Analysis of Secondary Codes

Through categorization and analysis of secondary codes, psychological and

Table 3. Three-level codes.

\begin{tabular}{|c|c|c|c|}
\hline Levellcoding/content & Number/times of mention & Level 2 coding/content & Level 3 coding/content \\
\hline Respect for others & $7 / 7$ & \multirow{4}{*}{ psychological changes } & 1 Impact of personal change \\
\hline Understand the etiquette & $6 / 7$ & & \\
\hline Reduced loneliness & $5 / 5$ & & \\
\hline Anti-frustration ability increased & $12 / 12$ & & \\
\hline Body Shape change & $4 / 5$ & \multirow{3}{*}{ physical changes } & \\
\hline Smile increases & $8 / 9$ & & \\
\hline Physical fitness enhancement & $13 / 14$ & & \\
\hline Lovers feel more secure & $1 / 3$ & \multirow{2}{*}{ evaluation of changes, } & 2 Impact of society change \\
\hline Positive social evaluation & $4 / 4$ & & \\
\hline Equal social status & $5 / 6$ & \multirow{3}{*}{ communication changes } & \\
\hline Increased social trust & $3 / 5$ & & \\
\hline Feelings of inferiority decrease & $4 / 7$ & & \\
\hline Bonus reward & $11 / 15$ & \multirow{2}{*}{ future financial security } & Impact of future changes \\
\hline Fixed wage protection & $9 / 13$ & & \\
\hline Expand employment channels & $5 / 7$ & \multirow{2}{*}{ future career basis } & \\
\hline Improved self-care ability & $8 / 10$ & & \\
\hline
\end{tabular}


physical changes are finally classified as the impact of personal changes, others' evaluation changes and communication changes are classified as the impact of social changes, and future financial security and future career foundation are classified as the impact of future changes.

Finally, three-level codes are formed, namely: 1) impact of personal changes, 2) impact of social changes, and 3) impact of future changes, as shown in Table 3.

\section{Conclusion}

1) Participation of disabled people in taekwondo training has a positive impact to help them return to society.

2) The positive impact of disabled people's participation in taekwondo on their return to society mainly including three categories: The impact of Personal changes, Social changes and Future changes.

The three categories are divided into six subcategories as follows:

a) Personal changes: Psychological changes and physical changes

b) Social changes: Evaluation of changes and communication changes.

c) Impact of future changes: Future financial security and future career foundation.

3) The frequency of thinking units in the original data is as follows: Bonus reward (11/15), Physical fitness enhancement (13/14), Fixed wage protection (9/13), Anti-frustration ability increased (12/12), Improved Self-care ability (8/10), Smile increases (8/9), Respect for others (7/7), Expand employment channels (5/7), Understand etiquette (6/7), Feelings of inferiority decrease (4/7), Equal social status (5/6), Reduced loneliness (5/5), Shape change (4/5), Positive social evaluation (4/4), Increase social trust (3/5), Lovers feel more secure (1/3). Among them, the most frequently mentioned factor is bonus award and the most subject mentioned factor is physical improvement.

\section{Conflicts of Interest}

The authors declare no conflicts of interest regarding the publication of this paper.

\section{References}

Chen, H. C. (2004). Personality Psychology. China Light Industry Press.

http://www.worldtaekwondo.org

https://www.paralympic.org/news/patu-apc-sign-agreement-grow-para-taekwondo

Li Q. (2010). Research on the Relationship between Physical Exercise and Mental Health of Physically Disabled Youth. Shaanxi Normal University.

Lin, X. W., Chen, Y., \& Song, B. F. (2011). Investigation and Analysis of Mental Health Status of Physically Disabled People. Shanghai Preventive Medicine, 23, 311-312.

Tang, Z. Y. (2005). Effects of Sports on Mental State of Disabled People. Chinese Clinical Rehabilitation, No. 48, 141-143.

Tang, Z. Y. (2005). Effects of Sports on the Mental State of Disabled People. China Clini- 
cal Rehabilitation, No. 48, 141-143.

Tian, M. J., Ed. (2000). Sports Training Science. People’s Sports Press.

Valliant, P. M., Bezzubyk, I., Daley, L., \& Asu, M. E. (1985). Psychological Impact of Sport on Disabled Athletes. Psychological Reports, 56, 923-929. 